Vol. LXVI 2015

\title{
OPERATIONALIZATION OF THE PROFESSIONAL RISKS ASSESSMENT ACTIVITY
}

\author{
IVASCU Victoria Larisa \\ Faculty of Management in Production and Transportation / Department of Management, Politehnica University \\ of Timisoara, Romania, larisa.ivascu@upt.ro
}

\section{CIRJALIU Bianca}

Faculty of Management in Production and Transportation / Department of Management, Politehnica University of Timisoara, Romania, cirjaliu.bianca@yahoo.com

\section{DRAGHICI Anca}

Faculty of Management in Production and Transportation / Department of Management, Politehnica University of Timisoara, Romania, anca.draghici@upt.ro

Abstract: Professional risks assessment approach (integration of analysis and evaluation processes) is linked with the general concerns of nowadays companies for their employees' health and safety assurances, in the context of organizations sustainable development. The paper presents an approach for the operationalization of the professional risk assessment activity in companies through the implementation and use of the OnRisk platform (this have been tested in some industrial companies). The short presentation of the relevant technical reports and statistics on OSH management at the European Union level underlines the need for the development of a professional risks assessment. Finally, there have been described the designed and developed OnRisk platform as a web platform together with some case studies that have validate the created tool. platform

Key words: interdisciplinary, risk assessment, Occupational Safety and Health (OSH), OnRisk

\section{Introduction}

The problem of professional or work risks assessment is a continuous one, present in the literature and also trained by academia, consulting companies and by non-governmental organization, but most debated by professional organizations (at national or international level), unions and work assurance companies. The problem severity (only at the European level) is shown by the statistics: "annually 2.3 million people around the world die from work-related causes, and out of those 167,000 in the EU27 (Figures 1a and 1b). Globally, four major causes of work-related deaths emerge: work-related cancer, work-related circulatory diseases, work-related communicable diseases, and occupational accidents (Figure 1)” [6]. Figures show

Figure 1: Figure title (Times New Roman, 10 pt., bold, center)

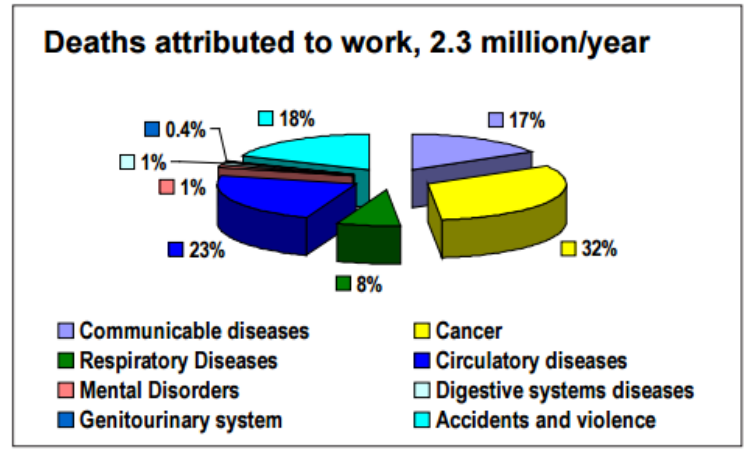

a

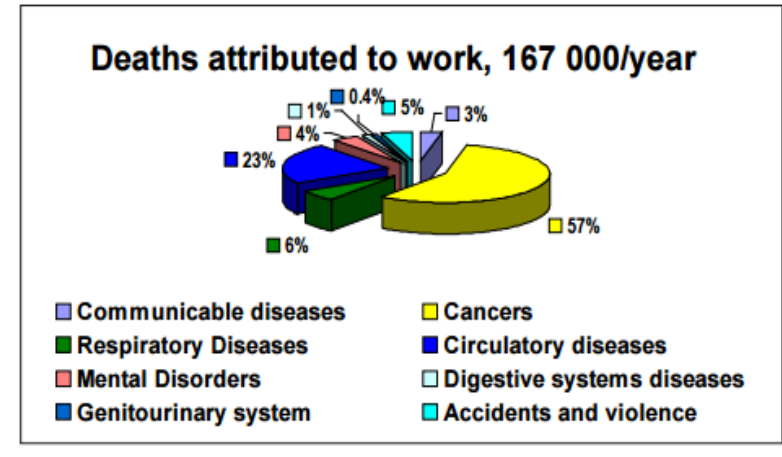

b

Source: [6]

The documents and initiatives of the European Agency for Safety and Health at Work (http://www.osha.europa.eu) together with The European Risk Observatory 
(http://osha.europa.eu/en/riskobservatory/index html) have underlined the severity of the problem, explain the phenomenon (by taking into consideration new conditions of the traditional risks development and occurrence, but also, new risks appearance) and conclude on identifying a strong the need for new, modern occupational risks assessment methods and tools.

Professional risks assessment approach (that refers to the integrated process of analysis and evaluation) is linked with the general concerns of work systems safety assurances and organizations environment policies development and implementation. Nowadays, organization responsibility (related to economic, environment and social field) is an important subject and announce the next Responsibility Society that will follow the Knowledge Base Society. There have been recognized that workplace safety and health is a mandatory action that have to be taken into practice for the benefit of both workers (employees of all categories) and the business itself (for managers and different stakeholders). Managers of all levels, specialists and researches are concern of the problems related to the working systems impact on the environment and also, on life quality. They support actions or initiatives that aim to diminish or eliminate the work accidents and occupational diseases, by using different methodologies of analyzing different risk categories impact or influence in practice (risk sources, the way of development, evolution, impact, effects and measure of diminishing or elimination) [7]. The following definitions could underline the importance of occupational risk assessment as part of the occupational safety and health management within an organization [2, 5]: (1) work accident means "the hurting of the human body and occupational acute intoxication that are happening during working process or during work duties that are causing the lost of work capacities at least for three days, invalidity or death"; (2) occupational disease "the disease produced by the exercitation of a profession, caused by physical, biological, chemical agents from the working environment and the overload of organs and systems during the working process".

Started from this brief overview of the problem there should be mention that [1] have proposed an integrated approach by considering specific "laws, the management systems view and OHS risk management throughout project life cycle and efforts" in order to couple OHS risk management to industrial safety practices including approaches using historical data and industrial interventions. This approach has been considered for our experimental researches, too.

\section{Relevant technical reports and statistics that refer to the OSH management at the European Union level}

The European survey of enterprises on new and emerging risks (ESENER) in 2013, has underlined importance of occupational health and safety information and knowledge. The survey results analysis (according to the European Framework Directive 89/391/EEC) aims to provide workers (in all Member States) with a common minimum level of protection from work related risks, but also it show the precise way in which these legislative provisions are translated into occupational safety and health management in the workplaces from one country to another, as well as by industry sector and organization size (ESENER, 2013). ESENER is developed within seven groups of countries (33 countries located in Europe) reflecting broadly similar contextual influences in terms of regulatory character and style, labor relations, social protection systems and other national regulatory, economic and social characteristics that are likely to be influential over the operation of regulatory requirements on workplace occupational safety and health (OSH) management.

The aim of the ESENER research was: (a) to provide a description and reasoned analysis of the most important factors affecting the way OSH is managed in the workplace (e.g. the environment); (b) to consider how this environment affects these three broad areas (e.g. the influence of the environment on workplace OSH practice). In order to achieve these aims a pragmatic and innovative mixed-methods approach was adopted involving desk research, secondary analysis of the ESENER data and new qualitative data collection. In addition, key expertise from each of the selected Member States was dynamically combined with broader expert views at both the European Union and wider international levels. ESENER results were structure in three main areas of interest, namely: occupational health and safety management, psychosocial risk management and the involvement of workers and their representatives [3]. One of the main conclusion of this research was related to OSH management and most its five determinants that act different from a country to another (underline by the macroeconomic analysis of the OSH policies related to each country). There have been underline the changes brought by globalization and its attendant labor market restructuring, budgetary deficits and decline in unionization, and that effect the development of diverse OSH management practices. In addition, different policies of regulatory bodies, social, economic and professional actors have rapid and profoundly influence the determinants of OSH management practices in all EU countries. 
The European Agency for Safety and Health at Work has established the priorities for OSH research in Europe for the next period, in the context of Europe 2020 strategy for smart sustainable and inclusive growth [4] (Table 1).

Table 1: Synthesis of the OSH research priorities in the European Union [4]

\begin{tabular}{|c|c|}
\hline Research Priorities & Expectations / Actions / Implications / Research Target \\
\hline $\begin{array}{l}\text { 1. Promoting good } \\
\text { health }\end{array}$ & $\begin{array}{l}\text { Keeping people healthy and active for longer has a positive impact on } \\
\text { productivity and competitiveness. Health and safety at work and OSH } \\
\text { researches have a role to play in delivering smart, sustainable and inclusive } \\
\text { growth ((EU-OSHA, 2013) report has been identified that a decisive scientific } \\
\text { knowledge is still lacking!); } \\
\text { A detailed approach should be developed at the theoretical and pragmatic level, } \\
\text { in order to identify exposure assessment methods to estimate the related risks } \\
\text { and appropriate risk management approaches to design workplaces to make } \\
\text { them as safe as possible could then be created; For some emerging risks there } \\
\text { is insufficient knowledge available to make reliable risk assessments. }\end{array}$ \\
\hline $\begin{array}{l}\text { 2. OSH in the } \\
\text { context of new } \\
\text { technologies (e.g. } \\
\text { those needed for new } \\
\text { energy policies, } \\
\text { climate adaptation, } \\
\text { future manufacturing) }\end{array}$ & $\begin{array}{l}\text { - New technologies benefits have to be clearly visible and their potential risks } \\
\text { have to be acceptable by society. This requires identifying and addressing } \\
\text { stakeholder and public expectations and responding to their concerns in order } \\
\text { to build confidence and to show that new technologies are well under control; } \\
\text { It is needed to identify and assess OSH risks associated with new technologies } \\
\text { and integrating OSH aspects in the development of new technologies and } \\
\text { processes. }\end{array}$ \\
\hline $\begin{array}{l}\text { 3. Economic activity } \\
\text { and occupational } \\
\text { injury and illness }\end{array}$ & $\begin{array}{l}\text { Researches has to discover and understanding the role of economic factors in } \\
\text { the etiology of workplace ill-health and the effects this has on the economic } \\
\text { prospects for workers, enterprises, and society is crucial for policy } \\
\text { development and to support decision making at enterprise and society levels. }\end{array}$ \\
\hline $\begin{array}{l}\text { 4. OSH research } \\
\text { findings has to be } \\
\text { strongly translated } \\
\text { into practical and } \\
\text { accessible } \\
\text { workplace solutions }\end{array}$ & $\begin{array}{l}\text { OSH research has to be focused on the transfer and translation of scientific } \\
\text { knowledge into practical, accessible workplace solutions and interventions. } \\
\text { It is important to integrate OSH research in the development of new } \\
\text { technologies and processes (prevention through design). }\end{array}$ \\
\hline $\begin{array}{l}\text { 5. Risk and OSH } \\
\text { communication }\end{array}$ & $\begin{array}{l}\text { - These are closely related to the transfer and dissemination of research results } \\
\text { (together with best practices of OSH and risk successful policies } \\
\text { implementation). } \\
\text { - Risk communication is particularly important in the context of new } \\
\text { technologies where there are uncertainties regarding the potential risks. There } \\
\text { is a need to strengthen risk communication research to identify efficient ways } \\
\text { of delivering timely and appropriate information on OSH to various target } \\
\text { audiences. }\end{array}$ \\
\hline
\end{tabular}

Within this priorities report [4] there have been identified some specific research topics related to occupational risk assessment as:

- The research priority of creating reliable tools for quantitative risk assessment that will generate better quantitative data for the potency/potential identification of carcinogenic, mutagenic and sensitizing substances. In addition, there is a research need for the validation and improvement of models for worker exposure assessment: measuring, modeling and risk assessment;

- Job specific risk assessment tools need to be developed to ensure safe working environments and also to identifying OSH topics that training programs should be geared to address. This would facilitate the transfer of existing OSH knowledge to green technologies, and the development of job specific risk assessment for green jobs, as well as identifying OSH training needs;

- As a result of the increasing use of biotechnologies in the industrial sector, there is a need to develop tools for risk assessment and prevention measures.

The brief overview of the most relevant technical reports and statistics that refer to the OSH management at the European Union level have underline the importance of this field and some particular aspects that should be targeted by the new researches in the field. Based on these considerations and new perspectives generated by EU regulations, the present paper will present a proposed approach for building an occupational risk assessment web platform named OnRisk (based on a knowledge application system). The theoretical researches have been the support for a knowledge application that has been implemented 
in small and medium size enterprises with the aim of reducing the time for evaluation and analysis (diagnosis, also) in order to improvement the risk assessment process and to discover quick and in time OSH problems. OnRisk platform is also, a support for the decision making process in the field of OHS.

\section{Description of the OnRisk platform design and development}

In the proposed methodology, after the establishment of the relation between the three areas of: risk management, sustainable development and relevant standards in the field, there have been developed the model proposed for the development of the OnRisk platform. The proposed integrated approach has joint together the principles of risk management, the concept of sustainability and the actual, related standards (Figure 2). It can be observed that the risk assessment is performed by taking into consideration the sustainability dimensions: economic, social and environmental. Technology dimension of sustainability is addressed separately, because in the adopted approach there have been considered that a fair balance is not achieved without the real and complex support of technology, thus the technology becomes a complex problem.

The approach is based on the legal and normative framework provided by each family of standards relevant to risk assessment and sustainability as: ISO 9000, ISO 14000, OHSAS 18000, ISO 26000 and ISO 31000. The OnRisk platform design and development were made as a Web platform that has a dynamic form to be updated according to the company's activities (practical requirements and activity specific).

Figure 2: The conceptual model used for the OnRisk platform development

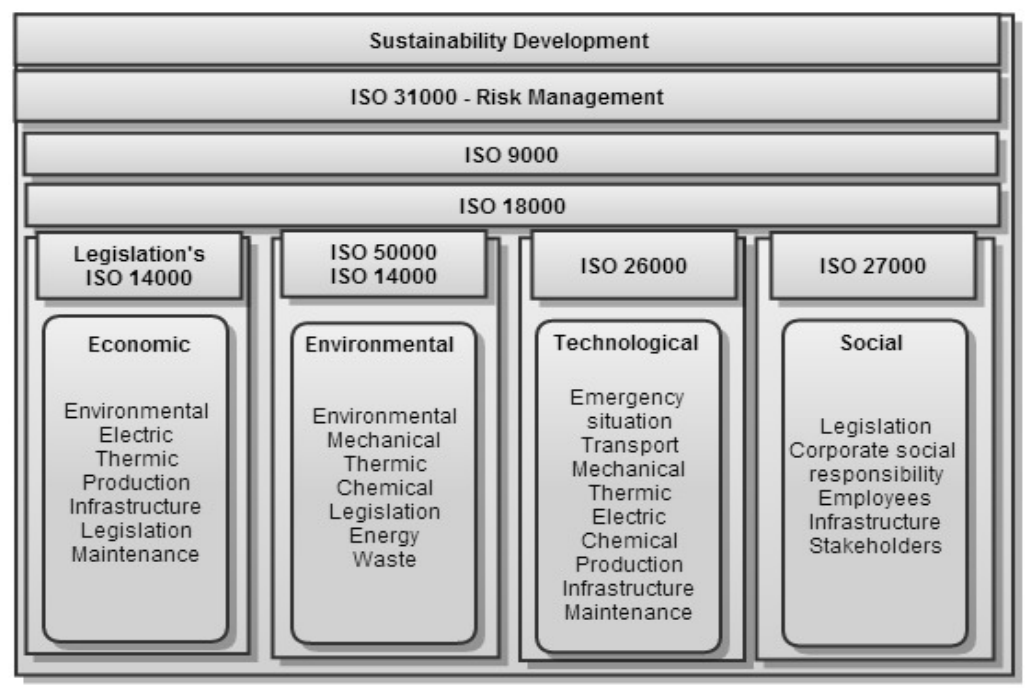

Source: authors own development

The OnRisk platform includes an improved methodology for effective risk analysis, unambiguous and prescribed for the aims of applying the principles of sustainability in companies that would integrate the proposed platform in their OHS practices (in order to have a quick response after the professional risk assessment). Because traditional risk assessment is performed without any formal description of the purpose of assessment or evaluation report produced at the end, the designed and developed platform aims to provide a well-defined set of information that describes in detail the subject evaluated, communication between company's stakeholders, and full documentation of the evaluation process and interpretation of the results (clear explanations of the assessment results and their meaning). The OnRisk platform was developed in order to be adapted for the changing of both internal and external environments of the enterprise and also to be up-date by the incorporation of new risks identified. This could be done using the „Add Category" option (or functionality created) or by developing add-ons facilities. The OnRisk platform was developed based on the read-write web, Web 2.0.

The platform implementation and exploitation is a good solution for generating added value in the company, identifying opportunities through risks identification and their optimal treating (management or mitigation). The created tool could assure a high rate of risk identification and avoiding their omission because of the developed risk database (started from a check-list of risks and based on their typology presented in the literature or in relevant standards). The major ideas behind the OnRisk platform development (architecture design and user friendly interface definition) are (see Figure 3):

- It was developed using the cloud tools as: Hyper Text Markup Language (HTML), Hypertext 
Preprocessor (PHP), MySQL facilities for data storage and manipulation, JavaScript and Google Charts;

- It is easy to be integrated within the existing enterprise information system in order to support the decision making processing when performance management claim measurements of specifics key performance indicators in the OHS field (to gain sustainable competitiveness);

- It allows operations of import of existing data from Excel files, CSV, XML, Text file (data collection is facilitated);

- It allows operation of export data in Excel, Word, PDF, XML, CSV, Media Wiki Table (facilitates that are used of final reports);

- The web platform dynamics solution allows changing knowledge base according to the existing requirements of each organization.

Figure 3: Print screen of the OnRisk platform (example of the risk identification and characterization)

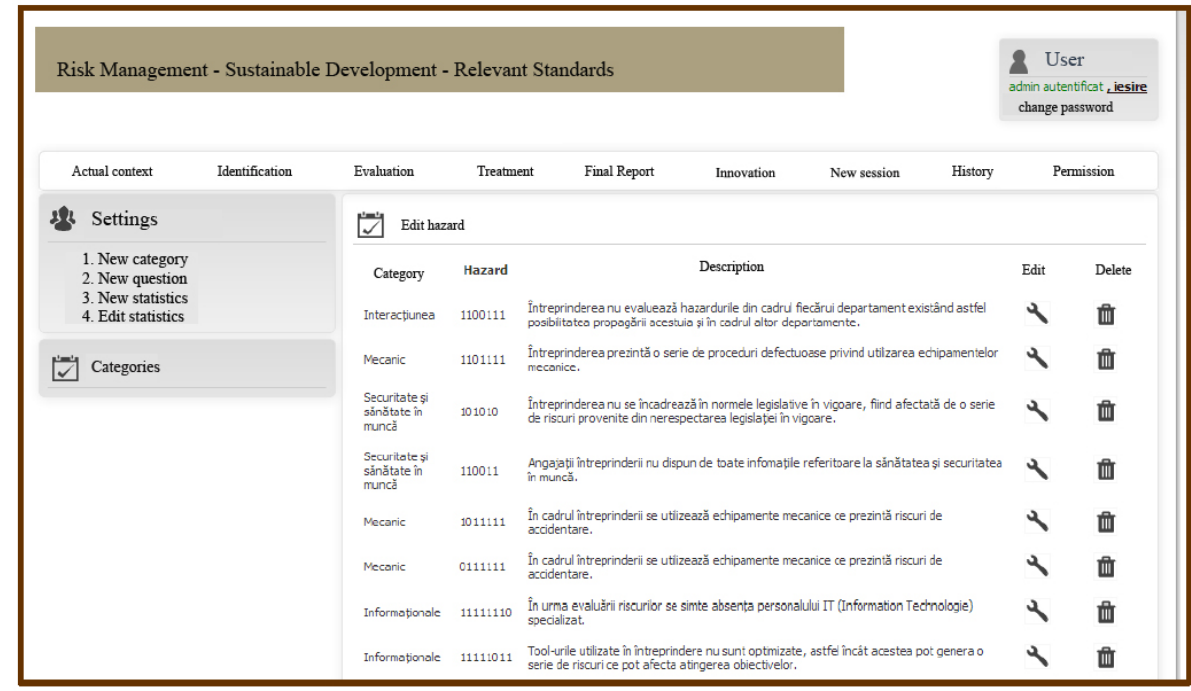

Source: authors own development

The platform functionalities are described in a systematic way and demonstrate the platform easy way of exploitation:

- Stage 1: Identification of hazards related to the sustainability dimensions as described in Figure 2. Hazards are organized in four categories: economic, social, environmental and technological. For each of them there have been defined a checklist with indentified, potential risks (as shown in Figure 2) and were taken into consideration related standards;

- Stage 2: For all the hazards that were identified in the previous stage, there were described (as a structured inventory) the associated risks. In addition, there have to be described for all the identified risks, the impact assessment (I), possible consequences (C) and the frequency of their appearance (F);

- Stage 3: is the main stage where the risk impact assessment is done. The identified risks have to be described related to the events that could have impact on the company's system and they should be described in accordance with the specific processes and/or activities. Once risks are identified, the platform assures automatic guiding for the next step development which is the risks assessment. Furthermore, the evaluator (researcher) can opt for a certain stage of the evaluation process using top labels (identification, evaluation, methods of prevention/treatment, final report).

- Stage 4: Risks treatment (or management) is the stage in which strategic measurements are proposed according to the characterization and evaluation parameters values that have been done in stage 2. During this stage there will be generated preventive and control measures for the identified risks (that will be considered for implementation). The information are listed in the final report of the risks assessment;

- Stage 5: is dedicated to the risks assessment final report establishment (refining and visualization). This report can be downloaded and printed, being a tool that can be used in future decisions taken at the enterprise level. This report contains preventive, control and communication measures and methods that contribute to enterprise OHS improvement and also, to the sustainable principles implementation. 
The main advantage of the designed OnRisk platform is its dynamics structure that creates the possibility to add, consider new sources of danger or other risks data. Companies evolve in dynamic and unpredictable business environment that provide new opportunities and strategies to improve their processes but also to be confronted with new risks categories. In these turbulent conditions, companies perceived differently depending on their operation capacity and their agility. Therefore the dynamic characteristics of the developed web platform allow adding new sources of danger, latent or emerging risks (that are considered in the assessment process).

\section{Conclusions}

According to the European statistics and reports (as presented in the paper, ESENER, EUOSHA), the risks assessment process is an important part of the OHS approach in organization in order to generate sustainable workplaces. In addition, the analysis and evaluation proposed process and the OnRisk developed platform are based on the general standards in the field of risks assessments as the: ISO 9000, ISO 14000, OHSAS 18000, ISO 26000 and ISO 31000.

The operationalzation of the risks assessment process in organization was tested and validated through some case studies, enterprises that operate in Romania. The research results delivered by the OnRisk reports have underlined additional risks that have be managed mainly in the field of their products and services impact on the environment (in the products end of life) and regarding the conditions of safety assurance.

The OnRisk platform has two main functions:

- It can be used for the risks assessment as it has been presented in the paper;

- It can be used for the training process of the new personnel that will work in the field, by teaching them how the analysis and evaluation took place in each stage of the proposed methodology and the meaning of the risk assessment report.

In the future, the researches should be focuses on the implementation of the platform in real companies (small and medium size companies are targeted), that supposes some adaptation of the assessment framework to the activity field and the specifics of those companies processes.

\section{References}

- Badri, A., Gbodossou, A., Nadeau, S., Occupational health and safety risks: Towards the integration into project management. Safety science, 50(2), 190-198, (2012).

- Erickson, P. A., Practical Guide to Occupational Health and Safety, Elsevier, (2003).

- ESENER, Analysis of the determinants of workplace occupational safety and health practice in a selection of EU Member States, (2013), On line at: https://osha.europa.eu/en/esener-enterprisesurvey/enterprise-survey-esener.

- EU-OSHA, European Agency for Safety and Health at Work, Priorities for occupational safety and health research in Europe: 2013-2020, (2013), On line at: https://osha.europa.eu/en/publications/reports/priorities-for-occupational-safety-and-health-researchin-europe-2013-2020.

- Takala, J., EU strategies and tools in occupational safety and health. In OH\&S Forum 2011 (p. 77), (2012).

- [6] Macdonald, D., Practical Industrial Safety, Risk Assessment and Shutdown Systems, Elsevier, (2003).

- Thébaud-Mony, A., Daubas, Letourneux, V., Frigul, N., Jobin, P., Santé au travail approches critiques. Paris, (2012). 